\title{
Polysulfone Ultrafiltration Membrane for Textile Industry Wastewater Treatment
}

\author{
P.T.P. Aryanti ${ }^{1, *}$ F.A. Nugroho ${ }^{1}$ F. Fachturahman ${ }^{1}$ I. A. Hidayat ${ }^{1}$ \\ ${ }^{I}$ Chemical Engineering Dept., Jenderal Achmad Yani University, Jl. Terusan Jendral Sudirman, Po Box 148, Cimahi, \\ West Java, Indonesia \\ *Corresponding author. Email: p.teta@lecture.unjani.ac.id
}

\begin{abstract}
Ultrafiltration (UF) membrane has become an alternative technology in water and wastewater treatment due to its low energy requirement. However, the application of conventional UF membrane is limited by its low rejection to soluble compounds, such as dyes in textile wastewater. In this work, a UF membrane was fabricated by blending polysulfone (PSf) with polyethylene glycol (PEG400), acetone, and $\mathrm{ZnO}$ in DMAc. The resulting membranes were utilized for textile wastewater treatment and then investigated in flux and naphthol rejection. The UF membrane that prepared by blending $20 \mathrm{wt} . \%$ PSf with $20 \mathrm{wt} . \%$ PEG400 and $1 \mathrm{wt} . \% \mathrm{ZnO}$ resulted in better performance compared to 16 and 18 wt.\% of PSf. The pure water flux was $60 \mathrm{~L} \cdot \mathrm{m}^{-1} \cdot \mathrm{h}^{-1}$. Reversible fouling on the membrane surface could be eliminated by a simple method (such as flushing), and therefore, the FRR value became higher (71\%). The rejection of Naphthol was low at $45 \%$.
\end{abstract}

Keywords: membrane preparation, textile wastewater, tight ultrafiltration, wastewater treatment

\section{INTRODUCTION}

Membrane technology has increasingly been used in wastewater treatment due to its low energy requirement to produce high-quality water products [1]. Among the available membrane technologies, membrane bioreactor (MBR), reverse osmosis (RO), and nanofiltration (NF) are widely used for textile waste treatment, either for disposal to the environment or reuse [2, 3]. Besides these membrane technologies, ultrafiltration (UF) membrane has been considered as an alternative technology due to its lower energy requirement with high rejection to colloids, suspended solids, and microorganisms [4]. However, the conventional UF membranes are limited by the low rejection of soluble compounds, such as dyes in textile wastewater [5]. It has been studied that the dye rejection by single-stage UF membrane generally does not exceed $90 \%$ [6].

Several studies have been conducted to improve the UF membrane selectivity by modifying the membrane surface (grafting and polymerization) [7] or altering the formulation of membrane solution [8]. Polysulfone (PSf) has widely been used in UF membrane preparation due to its good mechanical strength and good membrane-forming performances [9]. Modification of PSf membrane by introducing organic or inorganic modifiers has conveniently been used due to the simplicity of the method [10]. Mbuli et al. [11] synthesized a mixed matrix membrane by blending PSf with $0.5 \mathrm{wt} \%$ carbon-coated alumina supported Ni-TiO $\left(\mathrm{CCA} / \mathrm{Ni}-\mathrm{TiO}_{2}\right)$. The resulted membrane provided permeate flux around $105 \mathrm{~L} \cdot \mathrm{m}^{-2} \cdot \mathrm{h}^{-1}$ at $13.8 \mathrm{bar}$. Wenten et al. [4] blended $\mathrm{ZnO}$ in PSf solution and then coating on the PP membrane support. The existence of $\mathrm{ZnO}$ particles in PSf/PEG400/ZnO layer improved the membrane hydrophilicity, which decreased the water contact angle from $97.7^{\circ}$ to $77.1^{\circ}$. Aryanti et al. [5] investigated the influence of PSf and PEG400 ratio on the performance of UF membrane. They found that a stable flux was obtained when the PSf and PEG400 ratio was $1: 2$ with humic substances rejection up to $84 \%$. Said et al. [12] blended PSf with 20 wt.\% of polyetherimide (PEI). The resulted membrane had a permeability of $22.6 \mathrm{~L} \cdot \mathrm{m}^{-2} \cdot \mathrm{h}^{-1}$ at $4 \mathrm{bar}$, with a maximum rejection rate of RM20 (AO-74) of $68.5 \%$. Jiang et al. [13] found that UF membrane with a molecular size of 7310 Da provided a high rejection to reactive blue 2 (two) and direct dyes.

In this work, UF membrane was fabricated by blending PSf with PEG400, acetone, and $\mathrm{ZnO}$ nanoparticles in DMAc. The ratio of acetone and DMAC was fixed at $1: 15$, while the $\mathrm{ZnO}$ was added in 
$1 \%$ by weight of the total polymer weight. The concentration of polymer was varied to investigate its impact on membrane performance. The profile of permeate flux was observed during the textile wastewater treatment. The membrane selectivity was tested against naphthol-AS, which were used as coupling partners in some azo dyes preparation in the textile industry.

\section{MATERIAL AND METHOD}

\subsection{Materials}

PSf (UDEL-P3500 (MB7) was supplied by Solvay Advanced Polymers, while the DMAc was provided by Shanghai Jingsan Jingwei Chemical Co. Ltd with a purity of $99.9 \%$. PEG400 and acetone were obtained from local suppliers. The textile wastewater was obtained from one of the textile industries in Cimahi, West Java, Indonesia.

\subsection{Preparation of UF Membrane}

The preparation of PSf-based procedures referred to our previous work [5]. The flat-sheet UF membrane was prepared by immersing the casted membrane in a coagulation bath, which was filled with demineralized water. PSf, PEG400, acetone, and $\mathrm{ZnO}$ nanoparticle were blended in DMAc for 12 hours until homogenous. The concentration of PSf and PEG400 was varied from 16 to $20 \mathrm{wt} . \%$ and from 0 to $25 \mathrm{wt} . \%$, respectively. The ratio of acetone and DMAc was fixed at 1:15, while the concentration of $\mathrm{ZnO}$ nanoparticles was $1 \%$ by weight of the total polymer (PSf and PEG400).

\subsection{Determination of Permeate Flux and Rejection}

The water flux and rejection tests refer to our previous work [5]. Prior to the wastewater filtration, the UF pure (demineralized) water flux was tested against pure water and calculated by the following equation:

$J_{W 1}=V / A x t$

Where $J_{W l}$ is the permeate flux (in $\mathrm{L} \cdot \mathrm{m}^{-2} \cdot \mathrm{h}^{-1}$ ), $\mathrm{V}$ is permeated volume (in L), $\mathrm{A}$ is the membrane area (in $\mathrm{m}^{2}$ ), and $\mathrm{t}$ is measuring time (in an hour).

Membrane selectivity was identified by NaphtholAS rejection, as follows:

$R=\left(1-C_{p} / C_{f}\right)$

where $C_{p}$ and $C_{f}$ is the concentration of Naphthol in permeate and feed solution. UV-Vis was used to determine the concentration of Naphthol in the wastewater. The calibration curve was performed by fitting the absorbance against Naphthol-AS solution at the wavelength of maximum absorption. The standard curve of Naphthol concentration in textile wastewater was made by measuring the absorbance of various Naphthol concentrations.

\subsection{Determination of Flux Recovery Ratio}

After 60 minutes of filtration time, the UF membrane was cleaned by the flashing method using demineralized water for 15 minutes. Afterward, pure water flux is measured and identified as $J_{W 2}$. The flux recovery ratio (FRR) is determined using the following equation:

$\operatorname{FRR}(\%)=\left(J_{W 2} / J_{W 1}\right) \times 100$

Surface or reversible fouling $(R r)$ due to deposition of solutes on the membrane surface was calculated using equation (4).

$R_{r}=\left[\left(J_{W 2}-J_{p}\right) / J_{W 1}\right] x 100$

Meanwhile, internal or irreversible fouling $\left(R_{i r}\right)$ due to penetration of solutes into the inner membrane pore was calculated by equation (5).

$R_{i r}=\left[\left(J_{W 1}-J_{W 2}\right) /_{W 1}\right] \times 100$

\section{RESULTS AND DISCUSSIONS}

\subsection{The influence of polymer concentration on pure water flux}

The influence of polymer concentration (PEG400 and PSf) on the pure water flux of the resulting membrane is shown in Figure 1. It shows that the increase of PEG400 can increase the UF membrane water flux. It has been known that the PEG400 is hydrophilic and acts as a pore-former in the membrane structure. Inversely proportional to the effect of PEG400, the increase of PSf concentration in the polymer solution lowered the permeate flux. The rise of PSf concentration enhanced the solution viscosity, which exhibited the pore to growth and produced a smaller membrane pore. Consequently, lower pure water flux was obtained when the PSf concentration was raised. The highest water permeate flux was achieved when the concentration of PSf was $16 \mathrm{wt} \%$ and PEG400 of $25 \mathrm{wt} \%$. The average pure water flux was $122 \mathrm{~L} . \mathrm{m}^{-2} \mathrm{~h}^{-1}$ during 15 minutes of filtration test. 


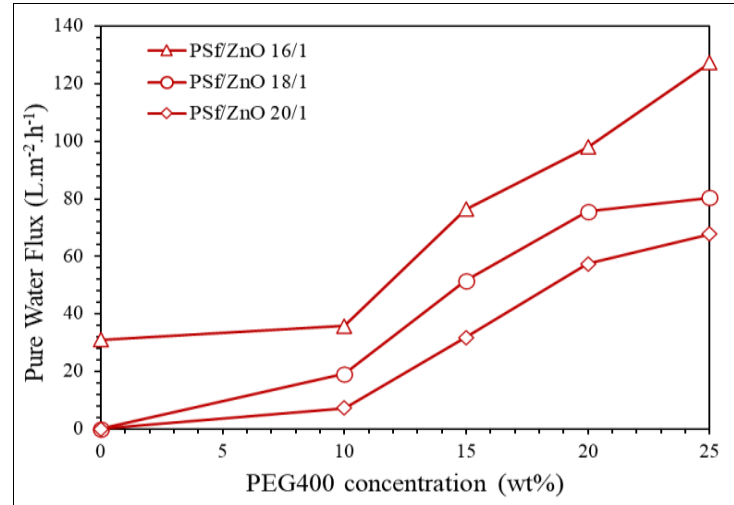

Figure 1 The effect of polymer concentration on pure water flux at $15 \mathrm{psig}$.

\subsection{The influence of PSf concentration on permeate flux and fouling during ultrafiltration of textile wastewater treatment}

Profile of permeate flux during 120 minutes of wastewater treatment using UF membrane is presented in Figure 2. The influence of PSf concentration was investigated at a fixed PEG400 concentration of 20 wt.\%. The profile of permeate flux was observed over the changes in the normalized flux, which was calculated by dividing the permeate flux at a certain operating time with the initial flux. The flux decline occurred at the first time of filtration. The build-up of solutes on the membrane surface reduced the quantity of permeate flux. Severe fouling was found at a PSf concentration of $20 \mathrm{wt} \%$ compared to lower PSf concentrations (16 and 18 wt.\%). At a concentration of 20 wt. $\%$ PSf, the flux decline was around $53 \%$ (from 57.32 to $26.96 \mathrm{~L} \cdot \mathrm{m}^{-2} \cdot \mathrm{h}^{-1}$ ). Meanwhile, lower flux decline was around $42 \%$ and $26 \%$ when the PSf concentration was 18 and 16 wt. $\%$, respectively. It was suggested that the increase of hydrophobicity of PSf enhanced the interaction of hydrophobic contaminants on the UF membrane.

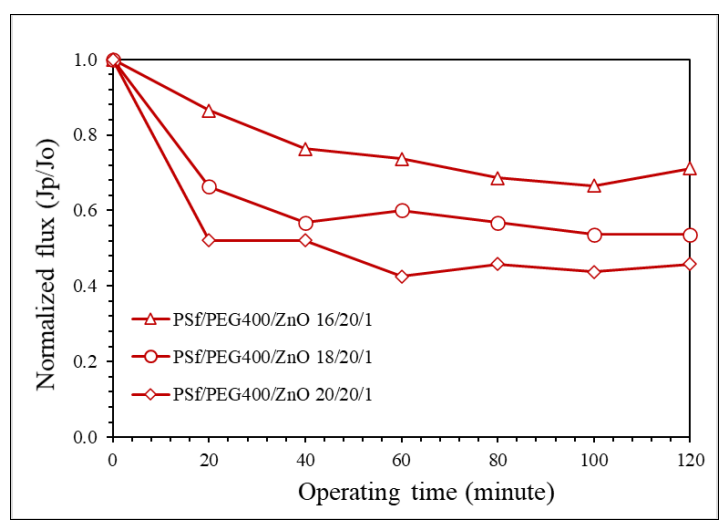

Figure 2 Profile of permeate flux during textile wastewater treatment at 15 psig.
Figure 3 shows the impact of PSf concentration on flux recovery ratio (FRR) and fouling formation on or in the membrane structure. Once the PSf concentration raised from 16 to $18 \mathrm{wt} \%$, the FRR decreased from $74 \%$ to $63 \%$. Further increase in PSf concentration to $20 \%$ by weight, the FRR raised to $71 \%$. The decrease of FRR was related to the types of fouling in the membrane structure. Although the decrease in fouling at 16 and 18 wt.\% PSf was lower, the fouling that dominated at low PSf concentrations was irreversible. The larger pores formed at low PSf concentrations made solutes easy to enter the membrane pores. Consequently, the irreversible fouling was more difficult to clean by the flushing method, and therefore, the FRR decreased. At 20 wt.\% of PSf concentration, some of the fouling was reversible on the membrane surface, which could be simply cleaned by the flushing method. The severe flux decline (as shown in Figure 3) was dominated by reversible fouling.

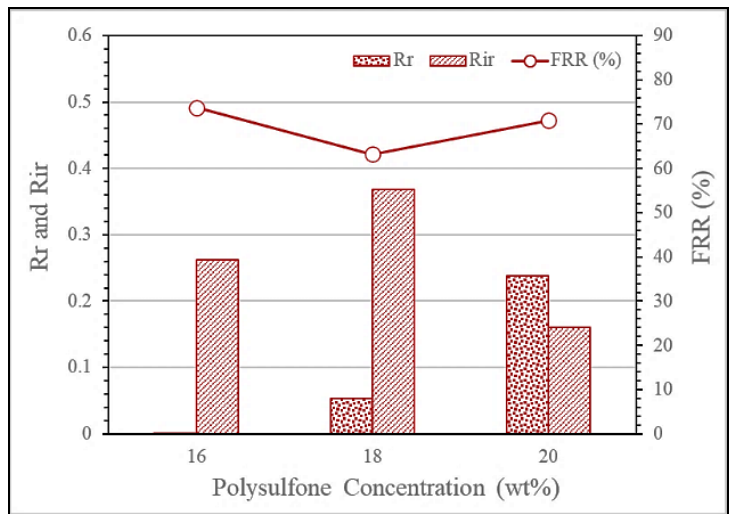

Figure 3 The influence of PSf concentration on Flux recovery ratio (FRR) and fouling formation in UF membrane structure

\subsection{The influence of polymer concentration on Naphthol rejection}

The Naphthol AS concentration in textile wastewater was analyzed using a UV-Vis spectrophotometer at a wavelength $(\lambda)$ of $294 \mathrm{~nm}$. The choice of wavelength number was determined from the highest wavelength in the naphthol solution analysis. Then, the concentration of Naphthol was varied to find the relation between absorbance and Naphthol concentration. The curve of absorbance at various concentrations of Naphthol is shown in Figure 4. This curve was used to determine the membrane selectivity based on the Naphthol rejection using Equation 2. 


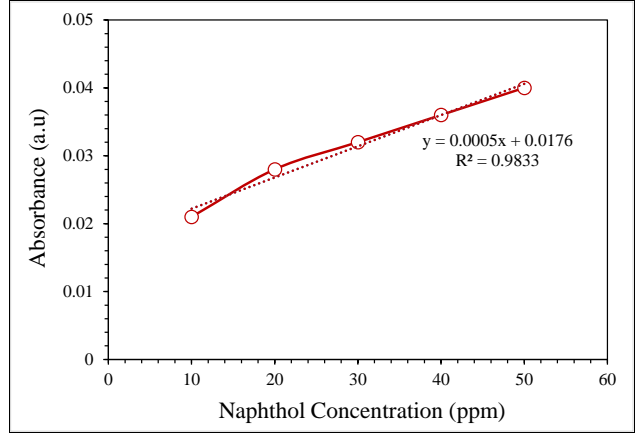

Figure 4 Absorbance curve of Naphthol solution at various concentrations.

The Naphthol rejection is presented in Figure 5. The influence of PSf concentration was investigated at a fixed concentration of PEG400 at $20 \mathrm{wt} . \%$. The highest rejection of Naphthol was achieved when 16 wt.\% PSf was used and operated at 15 psig. It was suggested that the high rejection of Naphthol contributed to irreversible (internal) fouling inside the membrane pore. The internal fouling reduced the effective membrane pore, and thus the rejection became high. Besides PSf concentration, Figure 5 also reveals the impact of operating pressure on Naphthol rejection. Higher rejection was found at lower operating pressure. The increase of operating pressure enhanced crossflow velocity on the membrane surface. This condition improved the coefficient of mass transfer of the solute pass through the UF membrane pore. As a result, the concentration of solute in the permeate increased, and consequently, it reduced the rejection value of the membrane.

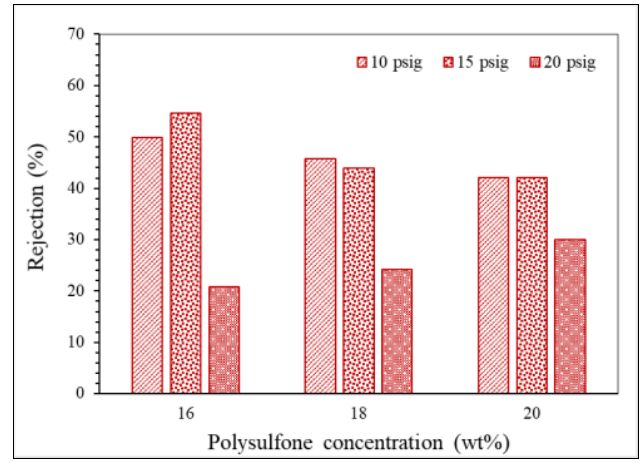

Figure 5 The influence of PSf concentration on the rejection of Naphthol at various operating pressure.

\section{CONCLUSION}

Polysulfone (PSf)-based UF membrane has been fabricated by mixing the polymer with PEG400, acetone, and $\mathrm{ZnO}$ nanoparticle in DMAc. The influence of polymer concentration is investigated to permeate flux and rejection of Naphthol. The UF membrane consisting of $20 \mathrm{wt} . \%$ of PSf, $20 \mathrm{wt} . \%$ of PEG400, and 1 wt.\% acetone provides better performances than 16 and 18 wt.\% of PSf. A high PSf content reduced irreversible (internal) fouling in the membrane structure.
However, another optimization is required to improve the membrane selectivity.

\section{ACKNOWLEDGMENT}

This research was supported by the Ministry of Education, Culture, Research, and Technology/National Research and Innovation Agency Republic of Indonesia through a program entitled: "Research Funding in Higher Education 2021", with Contract No.: 164/SP2H/LT/DRPM/2021 dated $18^{\text {th }}$ March 2021.

\section{REFERENCES}

[1] D. Sidabutar, E. Putri, N.A. Putri, S. Sakinah, dan P.T.P. Aryanti, Modification of PVC Membrane for Humic Substance Removal in Peat Water, Journal of Physics: Conference Series, 2020, 1477: p. 052014. 10.1088/1742-6596/1477/5/052014.

[2] N.C. Cinperi, E. Ozturk, N.O. Yigit, dan M. Kitis, Treatment of woolen textile wastewater using membrane bioreactor, nanofiltration and reverse osmosis for reuse in production processes, Journal of cleaner production, 2019, 223: p. 837-848.

[3] G. Sert, S. Bunani, E. Yörükoğlu, N. Kabay, Ö. Egemen, M. Arda, dan M. Yüksel, Performances of some NF and RO membranes for desalination of MBR treated wastewater, Journal of water process engineering, 2017, 16: p. 193-198.

[4] I.G. Wenten, K. Khoiruddin, A.K. Wardani, P.T.P. Aryanti, D.I. Astuti, dan A.A.I.A.S. Komaladewi, Preparation of antifouling polypropylene/ZnO composite hollow fiber membrane by dip-coating method for peat water treatment, Journal of Water Process Engineering, 2020, 34: p. 101158. https://doi.org/10.1016/j.jwpe.2020.101158.

[5] P.T.P. Aryanti, A.M. Noviyani, M.F. Kurnia, D.A. Rahayu, dan A.Z. Nisa, Modified Polysulfone Ultrafiltration Membrane for Humic Acid Removal During Peat Water Treatment, IOP Conference Series: Materials Science and Engineering, 2018, 288: p. 012118. 10.1088/1757-899x/288/1/012118.

[6] A. Schäfer, A.G. Fane, dan T.D. Waite, Nanofiltration: principles and applications, 2005: Elsevier.

[7] A. Wardani, D. Ariono, S. Subagjo, dan I. Wenten, Fouling tendency of PDA/PVP surface modified PP membrane, Surfaces and Interfaces, 2020, 19: p. 100464.

[8] E. Putri, D. Sidabutar, N. Putri, S. Sakinah, F. Nugroho, dan P. Aryanti, Preparation of Polyvinyl Chloride/ZnO Composite Ultrafiltration Membrane for Peat Water Treatment, in Journal of Physics: Conference Series, 2021: IOP Publishing, 
[9] M.S. Rameetse, O. Aberefa, dan M.O. Daramola, Effect of Loading and Functionalization of Carbon Nanotube on the Performance of Blended Polysulfone/Polyethersulfone Membrane during Treatment of Wastewater Containing Phenol and Benzene, Membranes, 2020, 10(3): p. 54.

[10] R. Singh, M.K. Sinha, dan M.K. Purkait, Stimuli responsive mixed matrix polysulfone ultrafiltration membrane for humic acid and photocatalytic dye removal applications, Separation and Purification Technology, 2020, 250: p. 117247.

[11] B. Mbuli, M. Mahlambi, C.J. Ngila, dan R. Moutloali, Polysulfone Ultrafiltration Membranes Modified with Carbon-Coated Alumina Supported NiTiO2 Nanoparticles for Water Treatment: Synthesis, Characterization and Application,
Journal of Membrane Science and Research, 2019, 5(3): p. 222-232.

[12] B. Said, S. M'rabet, R. Hsissou, dan A. El Harfi, Synthesis of new low-cost organic ultrafiltration membrane made from Polysulfone/Polyetherimide blends and its application for soluble azoic dyes removal, Journal of Materials Research and Technology, 2020, 9(3): p. 4763-4772.

[13] M. Jiang, K. Ye, J. Deng, J. Lin, W. Ye, S. Zhao, dan B. Van der Bruggen, Conventional ultrafiltration as effective strategy for dye/salt fractionation in textile wastewater treatment, Environmental science \& technology, 2018, 52(18): p. 10698-10708. 